\title{
QUALIDADE DA EDUCAÇÃO INFANTIL NA REDE MUNICIPAL DE ENSINO DE VITÓRIA DA CONQUISTA: UM OLHAR SOBRE O DISCURSO DAS COORDENADORAS PEDAGÓGICAS
}

\author{
QUALITY OF EARLY CHILDHOOD EDUCATION IN NETWORK HALL OF \\ CONQUEST OF VICTORY OF EDUCATION: A LOOK ON THE SPEECH OF \\ COORDINATING EDUCATIONAL
}

\author{
Relva Lopes Chaves SOARES ${ }^{1}$ \\ Sandra Márcia Campos PEREIRA ${ }^{2}$
}

RESUMO: O objetivo deste texto é conhecer a percepção das coordenadoras pedagógicas sobre a qualidade da EI na rede municipal de ensino de Vitória da Conquista - BA. É uma pesquisa qualitativa e a análise dos dados se deu a partir do uso dos postulados foucaultianos de: discurso, vontade de verdade, saber e poder. O estudo revela que: a) há sintonia das coordenadoras pedagógicas com a concepção de qualidade da Educação Infantil respaldada na cidadania infantil; b) as coordenadoras pedagógicas acreditam que é possível garantir às crianças uma Educação Infantil pública de qualidade; c) existe distanciamento do discurso científico e do discurso político das condições de oferecimento da Educação Infantil no município de Vitória da Conquista; d) a partir dos postulados Foucaultianos percebemos a resistência demonstrada por estas coordenadoras, que apesar das condições de trabalho a que estão submetidas, atuam em prol da melhoria da qualidade da Educação Infantil nas creches que estão sob sua responsabilidade.

PALAVRAS-CHAVE: Coordenação pedagógica. Educação infantil. Qualidade. Postulados foucaultianos.

ABSTRACT: The purpose of this paper is to know the perception of pedagogical coordinators about the quality of EI in municipal Vitória da Conquista education - BA. It is a qualitative research and analysis of the data was from the use of Foucault's postulates: speech, will to truth, knowledge and power. The study reveals that: a) there is line of pedagogical coordinators with the conception of childhood education quality supported in child citizenship; b) the pedagogical coordinators believe that it is possible to guarantee children a public early childhood education quality; $c$ ) there is detachment of scientific discourse and political discourse of offering conditions of early childhood education in the municipality of Vitoria da Conquista; d) from Foucault postulates perceive the resistance demonstrated by these coordinators, that despite the working conditions to which they are subjected, act for the sake of improving the quality of early childhood education in day care centers that are under their responsibility.

${ }^{1}$ Universidade Estadual do Sudoeste da Bahia (UESB), Itapetinga - BA - Brasil. Mestranda no Programa de Pós-Graduação em Educação. E-mail: relva.lc@ hotmail.com.

2 Universidade Estadual do Sudoeste da Bahia (UESB), Itapetinga - BA - Brasil. Professora Titular do Departamento de Pedagogia. E-mail: sandracampos.2005@uol.com.br. 
KEYWORDS: Pedagogical Coordination. Child education. Quality. Foucault's postulates.

\section{Introdução}

Neste texto, fizemos a análise do discurso das coordenadoras pedagógicas ${ }^{3}$ das instituições públicas de Educação Infantil ${ }^{4}$ de Vitória da Conquista - BA com o objetivo de conhecer a sua percepção sobre a qualidade da EI na rede municipal de ensino de Vitória da Conquista. Este estudo é parte da pesquisa: Coordenação pedagógica e qualidade da EI na rede municipal de ensino de Vitória da Conquista - BA, realizada no período de 2013 a 2015, cujo objetivo foi investigar a contribuição das coordenadoras pedagógicas para a construção do conceito de qualidade da EI da rede municipal de ensino de Vitória da Conquista - BA.

Para realização da pesquisa, o primeiro passo foi o levantamento bibliográfico na Biblioteca Digital Brasileira de Teses e Dissertações, no Portal de Periódicos Capes/MEC e nos sites da Associação Nacional de Política e Administração da Educação e da Associação Nacional de Pós-Graduação e Pesquisa em Educação. Posteriormente, localizamos livros e artigos que tratam da temática abordada e documentos ${ }^{5}$ do MEC/Conselho Nacional de Educação e Conselho Municipal de Educação, que orientam a organização da EI em âmbitos nacional e municipal.

O levantamento de dados ocorreu em 2014 com a aplicação de questionários. Esta opção justifica-se por possibilitar o alcance de um número significativo de participantes, pela garantia do seu anonimato e por se ajustar à disponibilidade de tempo dos sujeitos da pesquisa. Formado por seis questões objetivas e treze subjetivas, o questionário foi enviado por e-mail para as coordenadoras pedagógicas que aderiram à pesquisa.

A abordagem teórico-metodológica adotada neste estudo é respaldada nas teorizações e postulados do filósofo francês Michel Foucault. Neste contexto, na análise dos dados foram

\footnotetext{
${ }^{3}$ Em 2014 existiam 22 creches na rede municipal, mas apenas 18 contavam com coordenadoras pedagógicas. Destas, apenas 7 responderam o questionário, sendo 4 de creches municipais e 3 de creches conveniadas, todas situadas no perímetro urbano do município. Quanto à formação inicial das partícipes da pesquisa, 5 são licenciadas em Pedagogia, uma em Geografia e uma em História. Elas têm especialização em educação, experiência em sala de aula da Educação Infantil e na coordenação pedagógica.

${ }^{4}$ Doravante, utilizaremos no texto a sigla EI, no lugar de Educação Infantil.

5 Diretrizes Curriculares Nacionais para a EI (Resolução $\mathrm{n}^{\circ}$ 5, de 17 de dezembro de 2009) (CONSELHO NACIONAL DE EDUCAÇÃO, 2009) e Resolução nº 006/2012 (VITÓRIA DA CONQUISTA, 2012), que estabelece normas para o funcionamento de instituições de EI, jurisdicionadas ao sistema municipal de ensino de Vitória da Conquista.
} 
utilizados os conceitos de discurso, vontade de verdade, saber e poder (SOARES; PEREIRA; FERRAZ $\left.^{6}, 2016\right)$. Nas palavras das autoras:

\begin{abstract}
Segundo Foucault (2008, p. 132), discurso é "[...] um conjunto de enunciados, na medida em que se apoiem na mesma formação discursiva." Nesse sentido, o enunciado não é compreendido no sentido tradicional adotado na gramática, mas como "[...] produzido por um sujeito, em lugar institucional, determinado por regras sócio-históricas, que definem e possibilitam o enunciado." (MILANEZ, 2009, p. 19). (SOARES; PEREIRA; FERRAZ, 2016, p. 2-3).
\end{abstract}

$\mathrm{Na}$ ótica foucaultiana, o discurso é uma prática social, um ato essencialmente político sempre produzido em função das relações de poder, pois: “[...] o discurso não é simplesmente aquilo que traduz as lutas ou sistemas de dominação, mas aquilo por que, pelo que se luta, o poder do qual nos queremos apoderar." (FOUCAULT, 1999, p. 10). Deduz-se, então, que deter o discurso é deter o poder, o que explica a existência de uma engrenagem voltada à construção de uma ordem à qual os discursos são submetidos.

Foucault pulveriza e descentra o poder, percebendo-o disperso pelo tecido social, se espalhando, agindo capilarmente (VEIGA-NETO, 2014), o que representa uma ruptura com a ideia de que o Estado é a fonte de poder. Para o autor, o poder se exerce no Estado, mas não deriva dele. A este respeito, Machado (2006) chama a atenção para o fato de que Foucault não minimiza o papel do Estado nas relações de poder existentes nas sociedades, porém questiona a ideia de que o poder estaria localizado unicamente no Estado ou que a rede de poderes que atuam na sociedade seria um prolongamento da sua ação.

Nesta conjuntura, articula-se a construção de um regime de verdade, mediatizado pelo discurso, sendo possível afirmar que a verdade não existe, mas sim uma vontade de verdade, modificada ao longo da história, de acordo com o discurso científico que está vinculado às instituições que o proferem e às questões econômicas e políticas, cuja produção e veiculação são controladas, de modo quase exclusivo, por aparelhos políticos ou econômicos, etc. e que deve ser reativada em cada discurso (FOUCAULT, 1999).

Em tal contexto, Veiga-Neto (2014) assegura que o filósofo pensa o saber articulado ao poder, como uma estratégia e não como uma característica humana (natural, biológica, cerebral). Na abordagem foucaultiana, o saber é uma construção histórica e gera, ele mesmo,

\footnotetext{
${ }^{6}$ A pesquisa Coordenação pedagógica e qualidade da EI na rede municipal de ensino de Vitória da Conquista BA deu origem também ao artigo intitulado Coordenação pedagógica e qualidade da Educação Infantil: uma análise dos discursos das coordenadoras pedagógicas, de autoria de Relva Lopes Chaves Soares, Sandra Márcia Campos Pereira e Sintia Maria Gomes Ferraz que será apresentado no V Congresso Ibero-Americano e VIII Congresso Luso-Brasileiro da Anpae em setembro de 2016, em Goiânia, Goiás, Brasil.
} 
suas verdades, seus regimes de verdade. Os saberes se formam e se estruturam para obedecer a uma vontade de poder. Deste modo: "[...] os saberes se constituem com base em uma vontade de poder e acabam funcionando como correias transmissoras do próprio poder a que servem.” (VEIGA-NETO, 2014, p. 115).

Conforme Soares, Pereira e Ferraz (2016, p. 2):

[...] saber e poder se entrelaçam, na medida que estão diretamente imbricados. Para Foucault (MACHADO, 2014), o poder não existe, ele é exercido. Assim, ele não está localizado em um único ponto, centrado no Estado por exemplo, mas ele se manifesta na rede social, ou seja, o poder está disperso em vários lugares no tecido social, produzindo saberes. "[...] Estes saberes se constituem a partir das relações de poder, o poder fabrica o saber [...]" (FERRAZ, 2016, p. 20).

Enfim, o discurso compõe uma rede de poderes e saberes, fruto do contexto em que foi criado. O discurso é uma produção histórica e política.

\section{Breve caracterização da EI da rede municipal de ensino de Vitória da Conquista - BA}

Conforme Soares, Pereira e Ferraz (2016), em 20147 , 140 instituições de EI estavam em funcionamento em Vitória da Conquista $^{8}: 62$ da rede privada e 78 da rede pública, perfazendo um total de 10.990 matrículas: 2.758 crianças na creche e 8.232 crianças na pré-escola. Nesta conjuntura, as instituições públicas tinham a seguinte configuração: 01 creche estadual, 22 creches $^{9}$ municipais (01 na zona rural e 21 na zona urbana), e 55 escolas com turmas de EI ( 33 na zona rural e 22 na zona urbana), sendo que destas 08 escolas possuem salas para Atendimento Educacional Especializado (01 na zona rural e 07 na zona urbana) (INEP, 2014).

Dados do Sistema Integrado de Monitoramento Execução e Controle - SIMEC indicam que $71,7 \%$ das crianças de 04 a 05 anos e 18,7\% de 0 a 03 anos estão cursando a Educação Infantil em Vitória da Conquista, o que representa 28,3\% das crianças de 04 e 05 anos e $81,3 \%$ das crianças de 0 a 03 anos fora do sistema educacional. Este quadro evidencia o esforço que o município deverá realizar para alcançar a meta do Plano Nacional de

${ }^{7}$ O levantamento de dados da pesquisa aconteceu em 2014, por este motivo, tomamos este ano como referência para apresentarmos os números da EI do município.

${ }^{8}$ Vitória da Conquista é o terceiro maior município da Bahia com a população estimada de 348718

habitantes em 2017 (IBGE, 2017). Seu Produto Interno Bruto - PIB em 2013 era o quinto maior do estado, segundo a Superintendência de Estudos Econômicos e Sociais da Bahia - SEI (2013).

${ }^{9} \mathrm{Na}$ rede municipal de Vitória da Conquista, o uso da nomenclatura creche é comum a todas as instituições de EI, mesmo àquelas que atendem crianças da pré-escola. 
Educação - PNE 2014-2024 de universalizar, até 2016 a Educação Infantil na pré-escola para as crianças de 04 a 05 anos de idade e ampliar a oferta de Educação Infantil em creches de forma a atender, no mínimo, $50 \%$ das crianças de até 03 anos até o final da vigência do plano (BRASIL, 2014).

Ainda no âmbito do acesso à Educação Infantil pública em Vitória da Conquista, os dados indicam algumas questões que merecem atenção: a) a exclusão dos bebês do sistema público de ensino; b) a existência de apenas uma creche na zona rural; c) a inexistência de escolas específicas para Educação Infantil, implicando na alocação das turmas de pré-escola em escolas do Ensino Fundamental, cujos espaços e currículos invariavelmente não contemplam as especificidades do trabalho com a primeira infância.

Outra característica da EI de Vitória da Conquista que consideramos importante salientar é o alto percentual de creches conveniadas no município: quando a pesquisa foi realizada, 43,5\% das creches do município eram instituições conveniadas que não foram criadas por iniciativa do poder público, tiveram origem na iniciativa da sociedade civil, sobretudo dos movimentos sociais e religiosos. Estas instituições são contabilizadas no Censo Escolar como creches municipais, mas na verdade são instituições privadas cuja sobrevivência é possibilitada pelo convênio com a prefeitura municipal, uma vez que o município é responsável pelo pagamento dos funcionários e demais despesas utilizando, em contrapartida, o espaço das instituições. No que tange à gestão, a direção das creches conveniadas é definida segundo com critérios definidos em seus estatutos, ao passo que as diretoras das creches municipais desde 2009 são escolhidas por meio da eleição para diretores e vice-diretores como já acontecia nas escolas municipais desde 1993 (CHAVES, 2011).

Deve-se salientar também que, na rede municipal de ensino, o exercício da docência na Educação Infantil é realizado por monitoras e professoras ${ }^{10}$ : o trabalho com as crianças de 02 e 03 anos fica sob a responsabilidade de monitoras, enquanto professoras exercem a regência das turmas de 04 e 05 anos. Esta diferenciação incide diretamente na construção da identidade do trabalho docente na Educação Infantil pública do município, uma vez que o valor do salário das monitoras é inferior, além de não possuírem plano de carreira e não serem valorizadas profissionalmente. Esta condição indica diferenciação no tratamento destas profissionais e, consequentemente, precarização do atendimento às crianças menores (CHAVES, 2011).

Segundo Soares, Pereira e Ferraz (2016, p. 4):

${ }^{10}$ Optamos por utilizar as palavras "monitoras" e "professoras" por representar a realidade da rede municipal de ensino pesquisada, em que predomina o sexo feminino na docência na Educação Infantil.

Doxa: Rev. Bras. Psicol. Educ., Araraquara, v.19, n.2, p. 224-239, jul./dez. 2017. 
A coordenação pedagógica na rede municipal de ensino de Vitória da Conquista é exercida por professores (as) pertencentes ao quadro de efetivos. Como critério para exercer o cargo, exige-se a formação em Pedagogia ou outra licenciatura com especialização em educação, conforme a Resolução ${ }^{\circ}$ 006/2012 do CME. Não há nenhum documento oficial que regulamente o exercício da coordenação pedagógica na EI da rede municipal de ensino, visto que a mesma não possui o Regimento da EI. Por este motivo, a definição de coordenação pedagógica apresentada no Regimento das Escolas Municipais de Ensino Fundamental, resolução no 004/2004, do CME, tem sido utilizada para normatizar o trabalho das coordenadoras pedagógicas que atuam na primeira etapa da Educação Básica.

Finalmente, consideramos importante acrescentar que a Educação Infantil de Vitória da Conquista é regulamentada pela Resolução no 006/2012 do Conselho Municipal de Educação - CME. Pautada na Constituição Federal de 1988, na LDBEN 9394/96 e nas Diretrizes Curriculares Nacionais para a Educação Infantil, nos Parâmetros de Qualidade para a Educação Infantil e nos Parâmetros Básicos de Infraestrutura para Instituições de Educação Infantil, esta resolução representa um avanço para o município, pois aborda questões pertinentes à qualidade do serviço oferecido nas instituições de Educação Infantil, como: elaboração da proposta pedagógica, quantidade de crianças por adulto em sala de aula, condições de infraestrutura, atendimento às crianças com necessidades especiais, reafirmação da indissociabilidade entre o educar e o cuidar, currículo, avaliação, formação necessária para assumir a direção e coordenação pedagógica de uma instituição de Educação Infantil e para ser educador (a) desta etapa da educação básica, critérios para criação, autorização de funcionamento e credenciamento de uma instituição, bem como para sua inspeção, dentre outros. Entretanto, a resolução ainda não é cumprida na íntegra e o Conselho Municipal de Educação não possui as condições adequadas para realizar o acompanhamento e a fiscalização das instituições.

\section{Análise de dados}

O debate acerca da qualidade da Educação Infantil no Brasil é atual e necessário, visto que as pesquisas ${ }^{11}$ têm denunciado a negação da cidadania das crianças pequenas brasileiras, seja pela má qualidade do trabalho desenvolvido nas creches e pré-escolas, seja pela dificuldade de acesso ou exclusão do sistema de ensino, configurando a violação do seu direito constitucional e caracterizando as instituições de Educação Infantil como espaços, que contrariando a sua função pedagógica e sociopolítica estabelecida nas Diretrizes Curriculares

${ }^{11}$ A este respeito, ler Campos, Füllgraf e Wiggers (2006), Campos et al (2011). 
Nacionais para a Educação Infantil (CONSELHO NACIONAL DE EDUCAÇÃO, 2009), contribuem para a manutenção e acirramento das desigualdades socioeconômicas, étnicoraciais e regionais.

Neste cenário, Soares, Pereira e Ferraz (2016, p. 4-5) pontuam que:

[...] debater a qualidade da EI exige uma criteriosa reflexão sobre a forma de garantir a todas as crianças pequenas o direito a uma educação que possibilite o exercício da sua cidadania no cotidiano das creches e préescolas. Esta questão sobressai frente às marcas da história da educação da primeira infância no Brasil, polarizada entre o assistencialismo e a escolarização precoce, ainda presentes em muitas instituições, apesar da legislação e estudos sobre a educação das crianças pequenas a partir da década de 1980. Diante do exposto, é premente a necessidade de se consolidar a identidade das instituições de EI como espaços eminentemente educativos, em que as crianças de 0 a 5 anos vivenciem experiências significativas, pautadas no tripé educar-cuidar-brincar.

Questionadas sobre o conceito de qualidade em Educação Infantil, as coordenadoras pedagógicas que participaram deste estudo demonstraram compartilhar desta concepção de qualidade pautada no respeito às crianças e à promoção da sua cidadania. Para elas, uma Educação Infantil de qualidade:

É aquela que possibilita ações às crianças, de forma que esse trabalho estimule, provoque e acolha as iniciativas e relações entre elas. (CP2)

É a que promova o crescimento da criança nos vários aspectos do seu desenvolvimento, estimulando-a a superar desafios cada vez mais complexos para que conquiste a autonomia diante da vida. (CP3)

É uma educação que prioriza os aspectos humanos e físicos, que oferte à criança espaços adequados, profissionais qualificados e valorizados que garantam os direitos da criança e ainda, que tenha propostas sólidas embasadas no tripé: educar/cuidar e brincar. (CP4)

É aquela que possui espaços, materiais e estruturas físicas adequadas, não extrapolam o limite de alunos por turma, possui profissionais com perfil e qualificação profissional e tem como objetivo atender às necessidades das crianças em todos os seus aspectos: físico, cognitivo, emocional e social, respeitando-as e proporcionando-lhes atividades prazerosas. (CP7)

É o processo educacional onde a criança deve ser vista como um ser em constante evolução e que apesar da 'dependência' da orientação e acompanhamento de um adulto, ela também é um sujeito capaz de construir o seu próprio mundo. Esse processo deve ser realizado numa atmosfera totalmente lúdica, baseada no acesso a infinitos meios de aprendizagem, conduzidos por profissionais com a formação e perfil adequados. (CP6) 
Destaca-se também que as partícipes associam a consolidação deste paradigma de Educação Infantil à qualidade da formação docente das educadoras da primeira infância. De fato, para que exercício da cidadania às crianças pequenas seja oportunizado diariamente nas instituições incumbidas da sua educação e cuidado é essencial que tanto em sua formação inicial quanto na continuada as educadoras reflitam sobre a cidadania infantil e discutam meios de promovê-la, uma vez que as mesmas são essenciais na garantia da sua efetivação. Sobre esta questão, Soares e Jauris (2015) argumentam:

[...] urge a realização de uma séria reflexão sobre a forma como se estabelecem as relações entre educadores (as) e crianças na Educação Infantil a fim de que a cidadania infantil extrapole os documentos oficiais e os discursos teóricos e se efetive na prática. De acordo com Micarello (2013), para que isso aconteça, é fundamental que os educadores reconheçam-na, pois cabe-lhes o papel de garantir os meios para sua concretização. [...] Nesta perspectiva, a formação inicial e continuada dos (as) educadores (as) da Educação Infantil deve cumprir seu papel de possibilitar que eles (as) reflitam não só sobre a sua prática, mas, sobretudo sobre o seu papel e sobre a finalidade da Educação Infantil na atualidade. Para tanto, se apresentam questões como: o que é ser criança? O que é cidadania infantil? Acredito na criança como produtora de cultura? Eu, adulto, respeito às crianças e valorizo suas capacidades? Quais as melhores formas de intervir no processo de desenvolvimento infantil, promovendo a subjetividade infantil?

Ou seja, ao planejar e desenvolver o trabalho voltado às crianças de 0 a 5 anos, deve-se buscar romper com a postura que toma o adulto como referência primeira, e por isso é chamada de adultocêntrica, deslocando o foco para as crianças que, não mais compreendidas como objetos, passam a ter a sua subjetividade promovida, sendo priorizadas em todas as decisões relacionadas à sua educação e cuidado. Este, provavelmente é um dos maiores desafios postos àqueles (as) que se dedicam à consolidação desta nova identidade da Educação Infantil: romper com uma perspectiva reducionista de currículo, que subestima o potencial das crianças, tendo o adulto como referência primeira, em prol de um currículo que lhes possibilite exercer seus diretos de brincar, sentir, se expressar, participar, falar, escolher, criar e fazer, vivenciando, em um ambiente especialmente pensado e preparado para elas, interações positivas com adultos e outras crianças, permitindo-lhes a construção de significações sobre si mesmas e o mundo, enquanto desenvolvem maneiras mais complexas de pensar, sentir e solucionar problemas, em clima de autonomia e cooperação.

Neste sentido, Angotti (2009) destaca o brincar como elemento fundamental de um currículo sensível às especificidades desenvolvimento infantil, uma vez que o mesmo é o 
elemento constituinte das infâncias vividas intensamente. Cabe salientar que o brincar se fez presente nos discursos das coordenadoras pedagógicas participantes deste estudo que afirmaram a necessidade de garantir: que a relação indissociável entre educar/cuidar/brincar se transforme em realidade no cotidiano das instituições ( $\mathrm{CP} 1$ e $\mathrm{CP} 4)$, que as Diretrizes Curriculares Nacionais para a Educação Infantil sejam colocadas em prática ${ }^{12}(\mathrm{CP} 2)$ e que a ludicidade esteja presente no cotidiano das instituições (CP6 e CP7), além de reconhecer a brincadeira como uma das principais linguagens infantis (CP1 e $\mathrm{CP} 3)$ e relatar projetos bem sucedidos, cujo intuito era trazer para as instituições as músicas infantis e as brincadeiras tradicionais (CP5). O reconhecimento da importância do brincar pelas coordenadoras pedagógicas é um passo importante para que o direito à brincadeira não seja negado às crianças e, consequentemente, para que se melhore a qualidade da Educação Infantil, pois:

[...] a opção pelo brincar desde o início da Educação Infantil é o que garante a cidadania da criança e ações pedagógicas de maior qualidade. O brincar é a atividade principal do dia a dia. É importante porque dá o poder à criança para tomar decisões, expressar sentimentos e valores, conhecer a si, os outros e o mundo, repetir ações prazerosas, partilhar brincadeiras com o outro, expressar sua individualidade e identidade, explorar o mundo dos objetos, das pessoas, da natureza e da cultura para compreendê-lo, usar o corpo, os sentidos, os movimentos, as várias linguagens para experimentar situações que lhe chamam a atenção, solucionar problemas e criar. (KISHIMOTO, 2010, p. 01).

Esta perspectiva se reafirma quando as coordenadoras falam sobre as conquistas alcançadas junto às suas equipes de trabalho em direção à melhoria da qualidade da Educação Infantil:

O principal avanço é que grande parte dos profissionais que atuam nessa modalidade já possuem conhecimento sobre as reais necessidades das crianças pequenas, procuram formação na área e conseguem falar a língua da criança. Nesse grupo específico a contação de história, as dramatizações e as músicas são tão presentes quanto o banho e a alimentação. A ideia do cuidar também não se desvincula mais do educar e o brincar não é mais uma atividade aleatória. (CP1)

Já conseguimos entender que a Educação Infantil não é uma etapa de escolarização. E que o professor enquanto mediador precisa garantir os Direitos da Criança. (CP2)

Unificação do trabalho na creche onde todos buscam explorar um tema comum, respeitando as especificidades do grupo, mas com liberdade para

${ }^{12}$ As DCNEI determinam que todas as atividades desenvolvidas nas instituições de Educação Infantil devem ter como eixo as interações e as brincadeiras. 
criar e estimular as várias linguagens das crianças por meio de atividades desafiadoras. (CP3)

Com todos os percalços, creio, que conseguimos entender o que é educação infantil, e o potencial que as crianças tem, a resposta que elas podem dar quando estimuladas e desafiadas. (CP4)

Podemos depreender, a partir da leitura dos excertos, que as partícipes, ao pontuarem a vinculação entre educar e cuidar na rotina das crianças $(\mathrm{CP} 1)$, a recusa à perspectiva escolarizante de Educação Infantil (CP2), a necessidade de pensar as práticas pedagógicas a partir do respeito ao desenvolvimento das crianças e valorizando as múltiplas linguagens infantis (CP3) e o reconhecimento do potencial das crianças (CP4) reafirmam o conceito de qualidade da Educação Infantil apresentado inicialmente e, apesar das dificuldades encontradas na realização do seu trabalho ${ }^{13}$ têm conseguido contribuir para a construção de uma Educação Infantil que respeita as crianças, priorizando-as na construção das práticas pedagógicas a elas destinadas.

Tal constatação reforça a observação de Soares, Pereira e Ferraz (2016) acerca da forma como estas coordenadoras pedagógicas concebem seu papel:

[...] a formação das educadoras, o planejamento pedagógico, o 'assessoramento' e apoio às monitoras e professoras, a supervisão do trabalho em sala de aula, a pesquisa e organização de material que será utilizado nos planejamentos, a realização de reuniões, a promoção da articulação entre todos os membros da comunidade escolar em prol da aprendizagem das crianças e o estabelecimento de boas relações interpessoais com os membros da equipe foram ações que sobressaíram na maioria das respostas acerca das atribuições da coordenação pedagógica na EI, indicando que o grupo de coordenadoras reconhece a importância da parceria com as educadoras para a constituição da intencionalidade educativa, indispensável para a qualificação das práticas pedagógicas nas instituições de EI.

Neste contexto, diante das especificidades do exercício da coordenação pedagógica nas instituições de Educação Infantil, as respondentes enfatizam que sua função requer estudo e atualização constantes, bem como o conhecimento aprofundado do desenvolvimento infantil e da legislação educacional referente a esta etapa da educação básica, como se pode averiguar

${ }^{13}$ Conforme Soares, Pereira e Ferraz (2016, p.11): “[...] um dos maiores obstáculos à promoção da qualidade da EI na rede municipal de ensino é a falta de tempo para realizar estudos e planejamento com as equipes nas instituições; g) o exercício da coordenação pedagógica nas instituições de EI na rede municipal tem sido descaracterizado com a priorização de ações como organização de eventos, decoração, produção de materiais pedagógicos em detrimento à formação continuada e à mediação da construção da proposta pedagógica das instituições." 
nos trechos dos discursos de CP1, CP2, CP3 e CP5 em que elas definem a coordenação pedagógica na Educação Infantil ou elencam algumas atribuições da função:

Planejar priorizando conteúdos e metodologia que beneficie o entendimento da faixa etária;

Supervisionar a pratica do grupo de monitores para o cumprimento dos princípios que norteiam a Educação Infantil; (CP1)

É ter clareza dos princípios que norteiam a Educação Infantil para que de fato toda a equipe de trabalho seja envolvida num atendimento que respeite os direitos das crianças. (CP2)

É conhecer as fases de desenvolvimento das crianças para que possa, junto com os professores, planejar atividades que oportunizem o desenvolvimento das diversas linguagens em nossos educandos. (CP3)

Estudar frequentemente as teorias a fim de fundamentar o pensar e o fazer pedagógico dos monitores/professores. (CP5)

Em contraposição, CP7 afirma que ser coordenadora pedagógica na Educação Infantil: "É em primeiro lugar, você gostar muito de crianças pequenas e de trabalhar com atividades lúdicas [...]", revelando em seu discurso a influência do princípio da maternagem, que marcou a história da Educação Infantil desde sua origem, resultando na tardia profissionalização das educadoras da área (KISHIMOTO, 2002 apud ASSIS, 2006). A este respeito, Pereira (2015, p.10), recorrendo a Alves (2007) ressalta:

[...] convém lembrar que a presença isolada do amor como doação e justificativa para a atuação docente na EI acaba por se tornar um fator de desprofissionalização do trabalho, encobrindo a necessidade de investimentos em formação específica e valorização profissional. Ao mesmo tempo, oculta as contradições que degradam o trabalho dos professores, cada vez mais 'precarizado'.

Nesta conjuntura, merece atenção a presença deste tipo de discurso partindo de uma coordenadora pedagógica, que tem dentre suas principais atribuições a formação das educadoras, pois o mesmo reforça os estereótipos que ainda hoje pesam sobre a docência na Educação Infantil (de que é uma profissão feminina, que exige instinto materno e não requer formação específica), tendo relação direta com a maneira como a sociedade vê o trabalho realizado pelas educadoras da primeira infância, com a desvalorização do seu trabalho e com a construção da identidade destas profissionais e das instituições destinadas à educação das crianças pequenas. Neste contexto, convém relembrar que, apesar de inúmeros avanços no campo legal em direção à promoção da qualidade da educação da primeira infância, em 2013, 
a LDBEN, lei 9394/96 sofreu alterações que representam retrocesso com relação ao reconhecimento da necessidade da formação dos docentes em nível superior, uma vez que continua sendo admitida como formação mínima para atuar nas salas de aula da Educação Infantil a formação em nível médio na modalidade normal (BRASIL, 2013).

Assim, convém reforçar a importância do papel da coordenação pedagógica nas instituições de Educação Infantil na consolidação da profisssionalidade da docência da primeira infância. A superação da ambiguidade entre maternidade e docência requer, dentre outras ações, estudos, debates e reflexões constantes acerca da função sociopolítica da Educação Infantil e do papel das educadoras que se dedicam ao trabalho na primeira etapa da educação básica.

Destarte, todas as partícipes acreditam que é possível garantir às crianças uma Educação Infantil pública de qualidade, mas advertem que isso dificilmente acontecerá sem que o poder público assuma sua responsabilidade. Compreendem, portanto, que a qualidade do trabalho realizado nas creches e pré-escolas está diretamente relacionada ao investimento e à atenção que o poder público municipal dispensa a esta etapa da Educação Básica (CAMPOS, 2010). Sob esta ótica, ao avaliarem a qualidade da Educação Infantil na rede municipal de ensino, as coordenadoras pedagógicas desabafam:

Mas como falei anteriormente a cada ano que passa parece que há uma desresponsabilização de papeis. Esse ano vai entrar para a história faltou tudooooooooo. Arrisco a dizer que nem no tempo da Secretaria de Desenvolvimento Social foi tão precário assim! (CP1)

Penso que a educação pública ainda não consegue oferecer uma Educação Infantil de qualidade, visto que não existe uma fiscalização e consequentemente não há cobrança com relação a uma proposta de trabalho, bem como, não há disponibilidade de tempo para estudo e pesquisas a respeito da prática pedagógica para este público. Dessa forma, cada instituição trabalha como quiser, não havendo uma unidade na rede. $\mathrm{Na}$ instituição em que trabalho, embora existam divergências em relação à proposta a ser seguida, acredito que estamos conseguindo avançar, mas ainda não é a educação ideal. (CP3)

[...] há uma descontinuidade de proposta, cada instituição, ou melhor cada professor atua de forma que acha que deve ser, como citei, por falta de vontade da SMED, essa não tomou 'as rédeas' da educação infantil [...] (CP4)

Muito pouco, existe uma fala que já virou chavão: 'estamos estruturando para o ano seguinte', e anos passam e quase nada se faz, a começar pela estrutura física que não garantem o mínimo de conforto para as crianças, a Proposta que mesmo saindo do papel, não mudará muita coisa, pois depende de conhecimento, envolvimento, querer politico para injetar recursos nessa etapa. (CP4) 
As vezes penso, que é 'chover no molhado', para mim, são muitos, mas os desafios maiores são:

A falta de envolvimento (descaso) da SMED,

Desvalorização dos profissionais, que torna mais árdua a tarefa e fica difícil para o coordenador avançar nas propostas de trabalho. (CP4)

Hoje, avalio a rede municipal como regular, no ponto de vista administrativo. Por deixarem faltar espaço adequado, material pedagógico, administrativo e, principalmente humano para que as creches e escolas pudessem desenvolver da forma que deveria. Não posso ser hipócrita e dizer que está tudo perfeito! Sei das dificuldades que a educação dessa cidade passa e, principalmente da falta de compromisso e jogo de interesses de algumas pessoas que passaram pela administração da mesma. (CP5)

A leitura dos fragmentos denota o descontentamento das participantes quanto à gestão da Educação Infantil pela SMED. Neles podem ser identificados problemas que dificultam o oferecimento de uma Educação Infantil de melhor qualidade às crianças conquistenses: as poucas condições para a construção de um trabalho consistente nas instituições, a falta de acompanhamento do trabalho pela SMED, a falta de uma proposta pedagógica consolidada que de fato oriente o trabalho desenvolvido nas instituições, o fato da Educação Infantil não ser priorizada pela SMED. A estes podem ser somadas questões como: o exercício da docência nas turmas de creche por monitoras, a desvalorização destas profissionais (CHAVES, 2011) e a falta de tempo para realização da formação continuada nas próprias instituições e até mesmo do planejamento, como foi detectado por Soares, Pereira e Ferraz (2016).

A partir do discurso proferido pelas coordenadoras pedagógicas é evidenciado o distanciamento do discurso científico e do discurso político das condições de oferecimento da educação infantil no município de Vitória da Conquista. Diante da vontade de verdade de nossa época (FOUCAULT, 1999), os enunciados proferidos nos documentos oficias geralmente se aproximam daqueles proferidos pelos enunciadores autorizados (FOUCAULT, 1999) a produzir o saber sobre educação infantil. Todavia, a implementação da política por meio da ação do poder público não tem considerado nem o estabelecido em leis e documentos nem a produção científica sobre a temática.

Recorrendo novamente a Foucault, podemos destacar ainda a resistência demonstrada por estas coordenadoras, que apesar das condições de trabalho a que estão submetidas, atuam em prol da melhoria da qualidade da Educação Infantil nas creches que estão sob sua responsabilidade. Neste contexto, relembramos com o filósofo que as relações de poder não são fixas, mas móveis, reversíveis e instáveis, transformando-se a depender da conjuntura em que estão inseridas. Neste contexto, a resistência é inerente às relações de 
poder ou, nas palavras de Veiga - Neto (2014, p.123, grifo do autor): “[...] a resistência ao poder não é a antítese do poder, não é o outro do poder, mas é o outro numa relação de poder." Desta forma, a resistência ao poder se dá no interior da rede constituída pelo próprio poder, rede da qual ninguém escapa, visto que se estende por toda a sociedade e da qual as resistências são pontos que emergem no intrincado sistema de correlação de forças.

\section{Considerações finais}

A título de conclusão podemos afirmar que as coordenadoras pedagógicas das creches da rede municipal de ensino de Vitória da Conquista manifestaram sintonia com a concepção de qualidade da Educação Infantil respaldada na cidadania infantil, explicitada na legislação educacional em vigor e defendida por militantes e grande parte das (os) pesquisadoras (es) da área.

As coordenadoras pedagógicas acreditam que é possível garantir às crianças uma Educação Infantil pública de qualidade e afirmam que têm conseguido contribuir para a construção de uma Educação Infantil que respeita as crianças, priorizando-as na construção das práticas pedagógicas a elas destinadas. Além disso, reconhecem que sua função requer estudo e atualização constantes, bem como o conhecimento aprofundado do desenvolvimento infantil e da legislação educacional referente a esta etapa da educação básica.

No entanto, apontam impedimentos para a efetivação plena do direito a uma Educação Infantil de qualidade às crianças conquistenses: as poucas condições para a construção de um trabalho consistente nas instituições, a falta de acompanhamento do trabalho pela SMED, a falta de uma proposta pedagógica consolidada que de fato oriente o trabalho desenvolvido nas instituições, o fato da Educação Infantil não ser priorizada pela SMED

\section{REFERÊNCIAS}

ANGOTTI, M. Desafios da educação infantil para atingir a condição de direito e de qualidade no atendimento In: ANGOTTI, M. (Org.). Educação infantil: da condição de direito à condição de qualidade no atendimento. Campinas: Alínea, 2009. p.131-149.

ASSIS, M. S. S. de. Práticas de cuidado e de educação na instituição de Educação infantil: o olhar das professoras. In: ANGOTTI, M. (Org.). Educação infantil: para que, para quem, e por quê? Campinas: Alínea, 2006. p.87-104.

BRASIL. Plano nacional de educação 2014-2024: Lei n.13.005, de 25 de junho de 2014, que aprova o Plano Nacional de Educação (PNE) e dá outras providências. Brasília: Câmara 
dos Deputados, Edições Câmara, 2014. Série legislação n.125. Disponível em:

<http://www.observatoriodopne.org.br/uploads/reference/file/439/documento-referencia.pdf>. Acesso em: 13 nov. 2017.

BRASIL. Lei n. 12.796, de 4 de abril de 2013. Altera a Lei no 9.394 , de 20 de dezembro de 1996 que estabelece as diretrizes e bases da educação nacional, para dispor sobre a formação dos profissionais da educação e dar outras providências. Diário Oficial da União: República Federativa do Brasil: Poder Legislativo, Brasília, DF, 5 abr. 2013. Disponível em: <http://www.planalto.gov.br/ccivil_03/_Ato2011-2014/2013/Lei/L12796.htm\#art1>.Acesso em: 13 nov. de 2016.

CAMPOS, M. M.; FULLGRAF, J.; WIGGERS, V. A qualidade da educação infantil brasileira: alguns resultados de pesquisa. Cadernos de Pesquisa, São Paulo, v.36, n.127, p.87-128, jan./abr. 2006.

CAMPOS, M. M. (Coord.). Educação infantil no Brasil: avaliação qualitativa e quantitativa. São Paulo: Fundação Carlos Chagas/MEC/BID, 2010. (Relatório final)

CAMPOS, M. M. et al. A qualidade da educação infantil: um estudo em seis capitais brasileiras. Cadernos de Pesquisa, São Paulo, v.41, n.142, p.20-54, abr. 2011.

CHAVES, R. L. Diretrizes Curriculares Nacionais para a Educação Infantil: análise de seu impacto nos PPP das instituições municipais de Vitória da Conquista. 2011. Monografia (Especialização) - Universidade Estadual do Sudoeste da Bahia, Itapetinga, 2011.

CONSELHO NACIONAL DE EDUCAÇÃO. Fixa as Diretrizes Curriculares Nacionais para a Educação Infantil. Resolução n.5, de 17 de dezembro de 2009. Disponível em: <https://www.mprs.mp.br/media/areas/gapp/arquivos/resolucao_05_2009_cne.pdf>. Acesso em: 13 nov. 2016.

FOUCAULT, M. A ordem do discurso. 5.ed. São Paulo: Edições Loyola, 1999.

IBGE. Cidades e Estados do Brasil: Consulta de área, população e dados básicos dos municípios: Vitória da Conquista. Disponível em: <https://www.ibge.gov.br/geocienciasnovoportal/organizacao-do-territorio/estrutura-territorial/15761-areas-dosmunicipios.html? $\mathrm{t}=$ destaques $\& \mathrm{c}=2933307>$. Acesso em: 17 nov. 2017

INEP. Censo Escolar de Vitória da Conquista, 2014. Disponível em: <http://www.inep.gov.br>. Acesso em: 20 jun. 2015.

KISHIMOTO, T. M. Brinquedos e brincadeiras na educação infantil. Brasília, ago. 2010. Disponível em:

$<$ http://portal.mec.gov.br/index.php?option=com_docman\&view=download\&alias=6672brinquedosebrincadeiras\&category_slug=setembro-2010-pdf\&Itemid=30192>. Acesso em: 13 nov. 2017.

MACHADO, R. Foucault, a ciência e o saber. Rio de Janeiro: Zahar, 2006.

PEREIRA, J. R. A coordenação pedagógica na educação infantil: o que dizem a coordenadora pedagógica e as professoras? In: REUNIÂO NACIONAL DA ANPED, 37. 
2015, Florianópolis. Anais... Florianópolis: UFSC, 2015. Disponível em: <http://37reuniao.anped.org.br/wp-content/uploads/2015/02/Trabalho-GT07-3622.pdf>. Acesso em: 13 nov. 2017.

SEI. Estatísticas dos municípios baianos: território de identidade n.20: Vitória da Conquista. Salvador: SEI 2013.

SOARES, R. L. C.; JAURIS, R. B. A organização do trabalho pedagógico na Educação Infantil: a visão das monitoras. In: SIMPÓSIO DE PESQUISA E EXTENSÃO EM GRUPOS COLABORATIVOS E COOPERATIVOS, 2.; JORNADA DE ESTUDOS DO GEEM: DISCUTINDO A CONSTITUIÇÃO DOS SABERES ELEMENTARES MATEMÁTICOS NO CURSO PRIMÁRIO NO ESTADO DA BAHIA, 2., 2015, Vitória da Conquista. Anais... Vitória da Conquista: UESB, 2015. Disponível em: <https://proceedings.galoa.com.br/geem/geem2015/trabalhos/a-organizacao-do-trabalho-pedagogico-na-educacao-infantil-a-visao-dasmonitoras>. Acesso em: $12 \mathrm{dez} .2015$.

SOARES, R. L. C.; PEREIRA, S. M. C.; FERRAZ, S. M. G. Coordenação pedagógica e qualidade da educação infantil: uma análise dos discursos das coordenadoras pedagógicas. In: CONGRESSO IBERO-AMERICANO, 5.; CONGRESSO LUSO-BRASILEIRO DA ANPAE, 8., 2016, Goiânia. Anais... Goiânia: ANPAE, 2016. Disponível em: <http://www.anpae.org.br/iberoamericano2016/publicacao/cntnt/artigos/eixo_5/E5_A18.html >. Acesso em: 20 jan. 2017.

VEIGA-NETO, A. Foucault \& a educação. 3.ed. Belo Horizonte: Autêntica, 2014.

VITÓRIA DA CONQUISTA. Conselho Municipal de Educação. Fixa normas para o funcionamento de instituições de educação infantil, jurisdicionadas ao sistema municipal de ensino de Vitória da Conquista. Resolução n⿳0 006/2012. Vitória da Conquista, 2012.

\section{Como referenciar este artigo}

SOARES, Relva Lopes Chaves.; PEREIRA, Sandra Márcia Campos. Qualidade da educação infantil na rede municipal de ensino de vitória da conquista: um olhar sobre o discurso das coordenadoras pedagógicas. Doxa: Rev. Bras. Psicol. Educ., Araraquara, v.19, n.2, p. 224239, jul./dez. 2017. e-ISSN: 2594-8385.

Submetido em: 01/05/2017

Aprovado em: 30/07/2017 